\title{
A device for inverting the visual field of animals
}

\author{
JOHN ZIMMERMAN, MARTIN REITE, and JOHANN STOYVA \\ Department of Psychiatry, University of Colorado Medical Center, Denver, Colorado 80220
}

\begin{abstract}
A device for inverting the visual field of small animals is described. Binocular lenses are mounted in a lightweight, aluminum frame which, in turn, is secured to a surgically attached, dental acrylic skull cap. The construction of the device, and its usefulness when simultaneous electrophysiological recordings are desired, is described by illustrating the details of fabricating such a device for a cat.
\end{abstract}

Studies of the perceptual processes that underlie spatial localization and visual-motor coordination have frequently employed spatially rearranged visual feedback. In fact. the use of inverted. reversed, or displaced images in the study of perceptual adaptation dates back to at least the 19th century (Helmholtz, 1924, 1962; Stratton, 1897). Although the considerable body of literature that has resulted from these studies will not be dealt with in this short paper, a number of excellent reviews and theoretical sources are available (Carr. 1935, 1966; Canon, 1970; Day \& Singer. 1967; Ewert. 1930. 1936. 1937; Foley, 1938: Harris, 1965; Held \& Freedman, 1963; Hershberger \& Carpenter. 1972; Howard \& Templeton, 1966; Kohler, 1964: Smith \& Smith. 1962: Starch. 1910: Taylor, 1962).

Since perceptual adaptation to distorted vision involves physiological processes, the multidisciplinary approach of biopsychology. particularly the techniques of neurophysiologists. may be able to provide valuable information regarding the psychophysiological mechanisms underlying this complex phenomenon. Some recent animal experiments relating the effect of altered visual experience to changes in the neural substrate of the visual pathways, and to corresponding electrophysiological changes, illustrate the practicality of the neurophysiological approach (Blakemore \& Cooper. 1970; Hirsch \& Spinelli, 1971; Hubel \& Wiesel, 1959. 1962). Unfortunately, the use of animals as subjects for distorted vision experiments has been somewhat hindered by the lack of an adequate design for constructing a lightweight easily tolerated device that can be worn by an animal to alter its visual input. This paper describes a device for inverting the visual field of a cat in a way that is not only compatible with long-term electrophysiological recordings but is an integral part of such procedures.

\section{THE SKULL CAP}

Previous attempts to force animals to wear vision-distorting devices have utilized masks. made of

Supported by United States Public Health Service. National Institutes of Mental Health. Grant No. MH-19973. various materials. which were held in place by means of a supporting leather headgear. One such device. used for spatially displacing the visual image of chicks, was described by Hess (1956). Other devices. developed for cats, have been used to color filter visual input (Robinson \& Voneida. 1962) or to selectively pattern the risual input (Hirsch \& Spinelli. 1971). Foley (1940) was the first person to make use of a comparatively rigid aluminum frame to position an inverting lens system in front of a monkey's eyes. Even this device. however. relied on a less than optimal means of support since it was "held in place by a leather headgear lastened with straps and surgical adhesive (Foley, 1940)." Substantial improvement in the stability of the spatially rearranged image can be achieved by developing a rigid frame. securely attached to the animal's head so that the optics (prisms or lenses) can be precisely positioned in front of each eve.

We have designed and constructed such a device. Details of construction are shown in Figures 1 to 4 . The completed unit may be seen in Figure 5. A key feature of the device is that. to insure stability. the trame is secured to a dental acrylic skull cap ${ }^{1}$ that is surgically attached to the head as shown in Figure 1. Embedded in the skull cap are sockets connected to implanted depth and surface electrodes to monitor the electroencephalogram (EEG). the electromyogram (EMG), and the electrooculogram (EOG). The skull cap is cast from a common dental acrylic which is poured into a hollow rectangular mold $25 \mathrm{~mm}$ high and having inside dimensions of approximately $25 \mathrm{x}$ $40 \mathrm{mim}$. The mold need be no thicker than $5 \mathrm{~mm}$, and the bottom surface of it should be shaped to conform to the top of the animal's head. The mold should either be made of or sprayed with a nonstick compound such as Tetlon.

The surgical procedure for attaching the acrylic cap is relatively straightforward. With the animal under general anesthesia. and with its head positioned in a stereotaxic unit. a $5.6-\mathrm{cm}$ longitudinal midline incision is made. the scalp retracted. and the periosteum scraped away. Five or six No. 4-40 stainless steel screws are placed into holes drilled into (but not through) the skull with a dental drill. The 


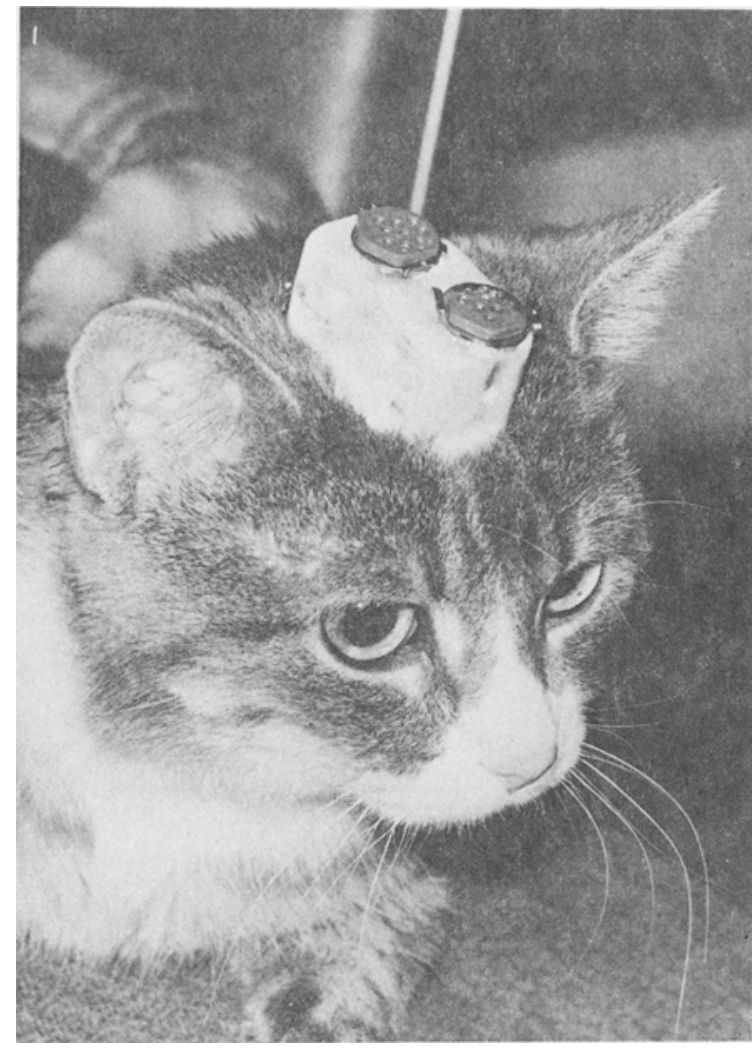

Figure 1. Surgically attached skull cap secured to top of cat's head. Note holes drilled into sides and end of skull cap to accept set screws in the metal frame (see Figure 3). Sockets visible at the top of the skull cap allow matching plugs to be quickly connected to implanted electrodes for electrophysiological recordings.

exposed skull should then be thoroughly cleaned with a 3\% solution of hydrogen peroxide and allowed to dry. The prefabricated mold is placed on the top of the skull and a thick mixture of the dental acrylic prepared. The mixture is then poured into the mold (and around the sockets if electrophysiological recordings are to be made) to a level a few millimeters from the top. After the material has set and the mold has been pried off, the scalp is sutured to conform to the shape of the skull cap. Excess skin may be trimmed away.

\section{THE ALUMINUM FRAME}

The basic frame is designed to fit over and be attached to the skull cap. The frame is constructed from a single piece of 18-ga aluminum sheet metal, measuring about $15 \mathrm{~cm}$ square (for a cat). Construction is as follows: first, form a rectangular opening, the exact size of the skull cap, near one edge of the flat piece of metal (as shown in Figure 2) by bending out four sides separated by cuts between them. Next, bend, cut, and shape the frame to cover the top, front, and sides of the cat's head. Use an epoxy glue to cement all overlapping sections together, both on the inside and the outside surfaces of the frame, to insure a structurally rigid unit. Drill several small holes through the sides of the skull cap opening of the frame and mark the location of these holes on the skull cap itself. Drill slightly larger holes at these locations and use a tap wrench to thread the holes in the frame so that set screws can be used to securely attach the frame to the skull cap.

Then, position the frame on the cat and mark the approximate position of the center of each eye on the front of the frame; remove it, and drill two $1 / 2$-in. "pilot" holes at these locations. Again place the frame on the cat, screwing it onto the skull cap to position it precisely, and look through these two "pilot" holes to determine the true position of the center of each eye. Scratch four cross marks on the outside surface of the frame that would intersect at the exact center of each eye when the cat is looking straight ahead. This is most easily accomplished if the cat is mildly sedated. Remove the frame again and drill two 1-in. holes centered on these marks. The completed frame should resemble the one shown in Figure 3.

\section{THE INVERTING LENS SYSTEM}

We used a telescope eyepiece containing a lens that is both fairly large in diameter (permitting a relatively large field of view) and that has a relatively short focal length, so that two such lenses mounted in a tube and separated by a distance equal to the sum of their focal lengths is not unduly long. ${ }^{2}$ This lens is a modified design 16-mm König formula. Each lens is a three-element system, consisting of a singlet, a doublet, and another singlet. According to the manufacturer, the lenses are free from chromatic and

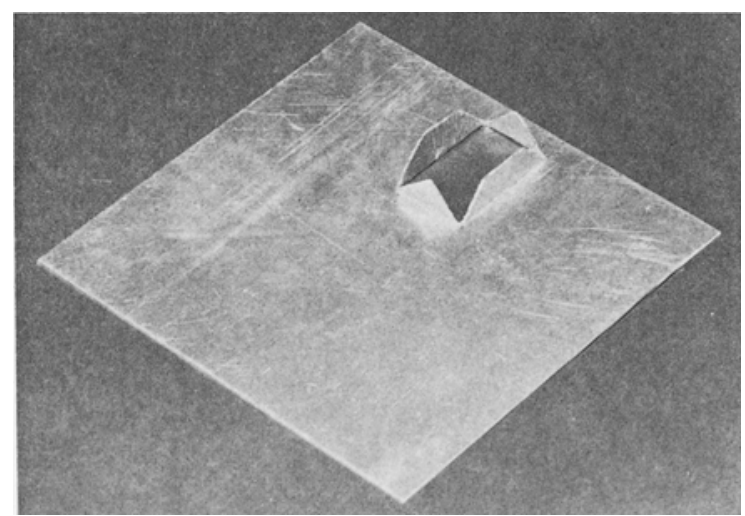

Figure 2. Single piece of aluminum sheet metal, about $15 \mathrm{~cm}$ square, with four flaps bent out $90 \mathrm{deg}$ from the surface to form a rectangular opening the exact size of the skull cap. 


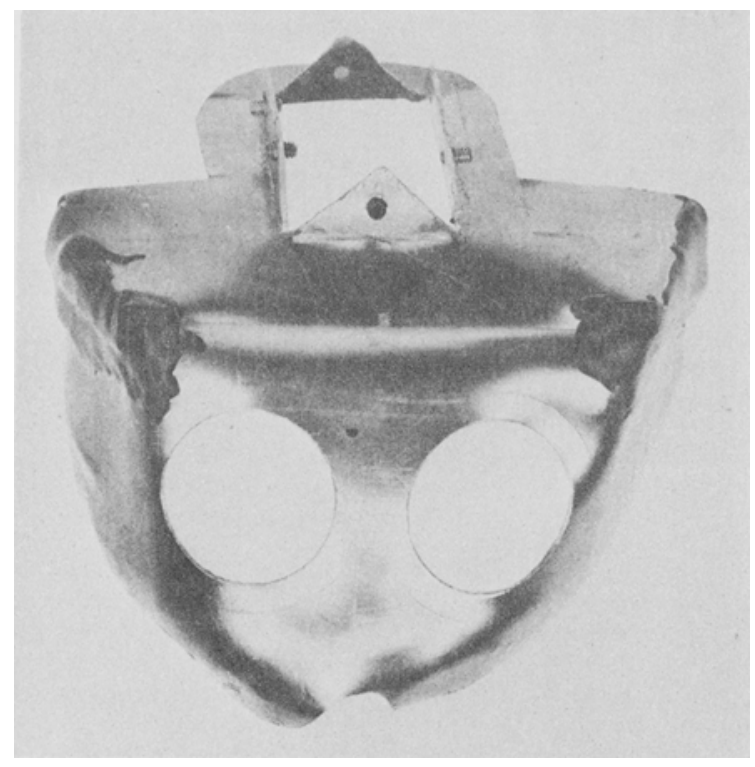

Figure 3. Metal frame after it has been shaped to cover the top, front, and sides of the cat's head. Note cutout portions for the cat's ears, eyes, and nose. Sides of skull cap opening have been drilled and threaded to accept six small set screws which are screwed into matching holes drilled into the skull cap on the cat's head(See Figure 1).

spherical aberrations, and the image field is flat and free from distortion.

Four such complex lenses are necessary to construct two image-inverting systems that rotate the visual array $180 \mathrm{deg}$ and that have near unit magnification. Two hollow aluminum tubes, measuring $6 \mathrm{~cm}$ long and having a $25.4-\mathrm{mm}$ outside diam, with a $5-\mathrm{mm}$ inner lip at one end (as shown in Figure 4), should be machined to accept the lenses. The $1 \frac{1 / 4}{4}$-in. outside diam barrel that comes with each lens can be discarded.

After the ocular tubes have been fabricated, but before mounting the lenses, the tubes should be made an integral part of the frame. Using a quick-acting (5-min) epoxy, each tube is temporarily glued to the frame in such a way that when the frame is securely attached to the skull cap, each tube is exactly centered upon and parallel with the optic axis. We chose to mount the tubes in a straight ahead position (parallel to each other) to allow the cat to fixate on relatively distant objects. However, the tubes can be tilted towards each other by any desired amount to facilitate convergence so that the cat can easily focus on nearby objects. Again it is advisable to work with a mildly sedated animal in order that this process be carried out as accurately as possible.

After the epoxy has partially dried, slight changes in the position and orientation of each tube can be made, if necessary, to accurately position the direction of the tube along the desired visual pathway and to insure that the inner lip of each tube is no further than $5 \mathrm{~mm}$ away from the surface of the eye. The frame may have to be repeatedly attached to the skull cap and the tubes temporarily glued in place, then unglued, and reset several times before both tubes are positioned properly. Once this has been achieved and the tubes satisfactorily glued in place

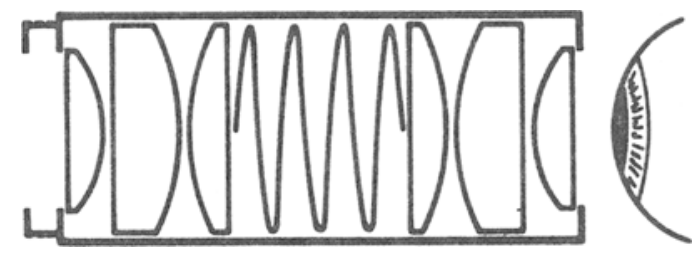

Figure 4. Schematic diagram of inverting lens system using two triple-element lenses, mounted back-to-back (eyepiece elements facing out) in a $6-\mathrm{cm}$-long aluminum tube. Lens elements are held against each end of the tube by a compressed coil spring between the two objective elements. Distance separating the two complex lenses is set by adjusting the retaining ring and screwing it into the tube so that the lenses are separated from each other by a distance that produces the best focused inverted image.

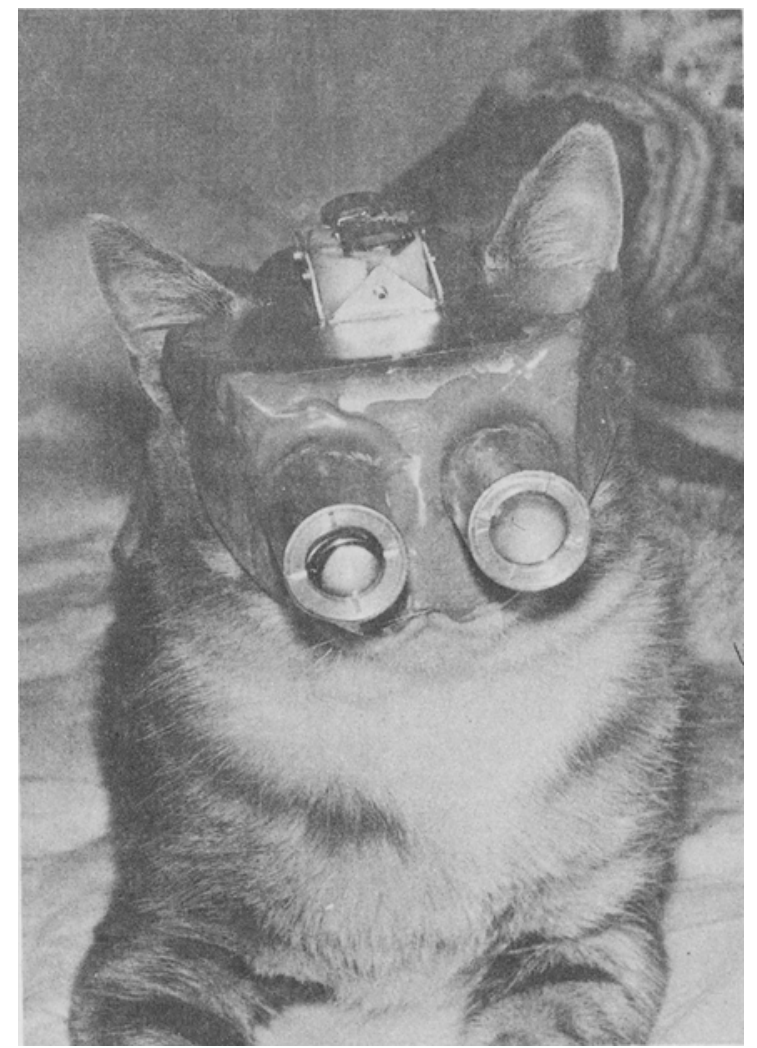

Figure 5. Cat wearing completed device. Binocular tubes, containing the inverting lenses, are glued to an aluminum frame which, in turn, is attached to a rigid skull cap which has been surgically anchored to the head. Note that the animal's nose and mouth are unobstructed. 
with the 5 -min epoxy, they can then be permanently attached to the frame using an industrial-strength epoxy applied at the tube-frame interface both on the inside and outside surfaces of the frame. Accurate positioning of the tubes with respect to the center of each eye is very important to insure a clear. sharply focused inverted inage.

After the epoxy has cured overnight, the lenses should be carefully inserted into each tube and arranged as illustrated in Figure 4. A large spring that barely tits in to the inside of the tube separates the two complex lenses from each other and holds each lens in place, one against the inner-lip portion of the tube and the other against a retaining ring threaded into the opposite end. The distance separating the optical centers of these two lenses is dependent upon how far the retaining ring is screwed into the tube; it should be set to that distance which produces the sharpest. most clearly defined inverted image. Also, the magnification of each lens-system tube should be equal. This can be açcomplished by looking binocularly at a ruler with a lens tube before one eye. The retaining ring may then be adjusted so that the ruler viewed through the tube, and the ruler viewed directly, subtend the same visual angle.

The completed device, shown attached to the cat in Figure 5, weighs only $6 \mathrm{oz}$. It offers a reasonably large field of view of over $55 \mathrm{deg}$ for each eye, with excellent clarity of the inverted image; and it can be worn almost indefinitely. ${ }^{3}$ Since the device becomes an integral part of the cat when it is screwed onto the skull cap. it not only resists efforts by the cat to dislodge it but also maintains the lenses accurately positioned in front of each eye.

\section{REFERENCES}

Blakemore. C.. \& Cooper, G. F. Development of the brain depends on the visual environment. Nature (London). 1970. 228. 477-478.

CANON. L. K. Intermodality inconsistency of input and directed attention as determinants of the nature of adaptation. Joumal of Experimental Psycholog: 1970. 84. 141-147.

CARR. H. A. An introduction to space perception. New York: Hatner. 1966 (Originally published 1935). Pp. 59-91.

DAY, R. H., \& SINGER. G. Sensory adaptation and behavioral compensation with spatially transformed vision and hearing. Psychological Bulletin, 1967. 67. 307-322.

Ewert, P. H. A study of the effect of inverted retinal stimulation upon spatially coordinated behavior. Genetic Psychologv Monographs. 1930. 7. 177-363.

EWERT. P. H. Factors in space localization during inverted vision: I. Interference. Psychological Review. 1936. 43. $522-546$.

EwERT. P. H. Factors in space localization during inverted vision: 11. An explanation of interference and adaptation. Psychological Revien. 1937. 44. 105.116.

FolEY. J. P. Empirical approaches to the problem of space perception. Psychological Bulletin, 1938, 35, 409-422.

Foley. J. P. An experimental investigation of the effect of prolonged inversion of the visual field in the rhesus monkey (Macaca Mulutta). Journal of Genetic Psichology. 1940 56. $21-51$

Harris. C. S. Perceptual adaptation to inverted. reversed and displaced vision. Psychological Review, 1965. 72. 419.444.

Held, R., \& Freedman, S. J. Elasticity in human sensorimotor control. Science. $1963,142,455-462$.

Helmholtz. H. L. F., von. Treatise on physiological optics (Vol. 3)(J. P. C. Southall, Ed. and trans.). New York: Dover. 1902. (Originally published by Optical Society of America. 1924.)

Hershberger, W. A., \& Carpenter, D. L. Adaptation 10 inverted retinal polarity: What's up. Bishop Berkeley? Journal of Experimental Pyychology, 1972, 94. 261-268.

Hess. ECKHARD H. Space perception in the chick. Scientitic American. 1956. 195. 71.80.

Hirsch, H. V. B.. \& Spinelli, D. N. Modification of the distribution of receptive field orientation in cats by selective visual exposure during development. Experimental Brain Reseurch. 1971, 13, 509-527.

Howard. 1. P., \& TEMPLETon, W. B. Human spatial orientation. New York: Wiley. 1966

Hubel, D. H., \& WIEsel, T. N. Receptive fields of single neurons in the cat's striate cortex. Journal of Physiology. 1959, 148, 574.591.

Hubel, D. H., \& Wiesel, T. N. Receptive fields, binocular interaction and functional architecture in the cat's visual cortex. Joumal of Physiology, 1962, 160. 106-154.

KOHLER, I. The fornation and transformation of the perceptual world. (Translated by $\mathrm{H}$. Fiss). Psychological Issues. Monograph 12.1964. 3.

Robinson. J. S.. \& Voneida, T. J. Mask for controlling visual input in cats. Science. 1962, 135, 962.

Sмiтh, K. U., \& Sмiтh, W. K. Perception and Motion: An analysis of space-structured behavior. Philadelphia: Saunders. 1962.

Starch, D. A demonstration of the trial and error method of learning. Psichological Bullerin. 1910. 7, 20-23.

Stratton, $G$. M. Vision without inversion of the retinal image. Psychological Review. 1897. 4. 341-360 and 463-481.

TAYLOR. J. G. The behavioral basis of perception. New Haven: Yale University Press. 1962.

\section{NOTES}

1. We used Kerr Formatray, available from a local dental supply store.

2. Available from University Optics. Inc. 2122 East Delhi Road. Ann Arbor. Michigan 48106.

3. Consistent with the inference that the animals were actually urilizing this upside-down and backwards visual information are several behavioral observations made while cats were wearing such inverted vision devices: (a) The initial reaction of all three cats tested. when first forced to wear the vision-inverting device, was an attempt to escape the inverted image by walking backwards. (b) When the cats were observed walking down a long hall. they invariably kept walking into the wall in an effort to avoid doing just that. (c) During the initial period of adaptation. the cats were frequently observed to move in a direction just the opposite of that required for a particular task. such as walking into the edge of an open door instead of through the opening.

(Received for publication May 6. 1975; revision received July 15.1975 .) 